\title{
Solubility and dissolution studies of tibolone polymorphs
}

\author{
Rudy Bonfilio, ", Marília Cristina Oliveira Souza ${ }^{1}$, Jockastta Silva Leal', Olímpia Maria Martins \\ Santos Viana ${ }^{1}$, Antônio Carlos Doriguetto², Magali Benjamin de Araújo ${ }^{1}$
}

\begin{abstract}
${ }^{1}$ Department of Food and Medicines, Faculty of Pharmaceutical Sciences, Federal University of Alfenas, Alfenas, MG, Brazil, ${ }^{2}$ Laboratory of Crystallography, Institute of Chemistry, Federal University of Alfenas, Alfenas, MG, Brazil
\end{abstract}

\begin{abstract}
Different solid forms of an active pharmaceutical ingredient can have distinct chemical and physical characteristics. In this work, we studied the solubility and dissolution properties of the described tibolone polymorphic forms (I and II). Both forms were successively recrystallized and characterized by powder X-ray diffraction and attenuated total reflection infrared spectroscopy. Equilibrium solubility and dissolution profiles were performed for both forms. Solubility studies demonstrated that form II is statistically more soluble in water, $0.01 \mathrm{~mol} \mathrm{~L}^{-1} \mathrm{HCl}$ and $\mathrm{pH} 4.5$ acetate buffer. The solubility of forms I and II were explained in terms of crystal packing. Dissolution tests of tablets showed a lower release of polymorphic form II than form I from tablets. The results showed an impact of polymorphism on the quality of tibolone tablets and suggest that tibolone forms I and II can show distinct interactions with pharmaceutical excipients used in tablets. Therefore, only form I is acceptable for the preparation of tablet forms. Based on our results, we propose the quality control on tibolone raw materials using X-ray diffraction analysis and attenuated total reflection infrared spectroscopy.
\end{abstract}

Keywords: Tibolone/polymorphs. Powder X-ray diffraction/methods. Infrared spectroscopy/methods. Solubility/drug effects. Dissolution/analysis.

\section{INTRODUCTION}

It is known that different forms of solids for an active pharmaceutical ingredient (API) can show different chemical and physical characteristics, which will affect the manufacturability, performance, and/or quality of a drug product (Karabas, Orkoula, Kontoyannis, 2007). Among the physicochemical properties that can influence the quality of APIs, solubility and dissolution rate are key because they are directly related to bioavailability (Delori, Friščić, Jones, 2012). Therefore, the study of these properties for different crystalline forms of any drug substance is of great importance.

Tibolone (17-hydroxy-7 $\alpha$-methyl-19-nor-17 $\alpha$ pregn-5(10)-en-20-yn-3-one), also known as Org OD14, $17 \alpha \mathrm{MNa}$ or 7 alpha, was patented in 1967 by the company Organon ${ }^{\mathrm{TM}}$ (De Jongh, Van Vliet, 1967). It is a hormonal substance with a tissue-specific action used in

\footnotetext{
*Correspondence: R. Bonfilio. Departamento de Alimentos e Medicamentos, Faculdade de Ciências Farmacêuticas, Universidade Federal de Alfenas. Rua Gabriel Monteiro da Silva, 700, 37130-000 - Alfenas - MG, Brasil. E-mail: rudybonfilio@gmail.com
}

the treatment of climacteric symptoms and the prevention of osteoporosis in postmenopausal women (Kenemans, Speroff, 2005). Tibolone is practically insoluble in water and is commercialized as $2.5 \mathrm{mg}$ oral tablets (brand name: Livial $^{\mathrm{TM}}$, produced by Akzo Organon ${ }^{\mathrm{TM}}$ ).

To the best of our knowledge, two crystalline structures have been described for tibolone to date. The first crystal phase, named form I, was determined by Declercq, Van Meerssche, Zeelen (1984) in a P2 monoclinic space group $(\mathrm{a}=6.542(2) \AA, \mathrm{b}=41.213(9)$ $\left.\AA, c=6.678(2) \AA, \beta=101.64(2)^{\circ}\right)$. The second known phase, named form II, was found some years later by Schouten, Kanters (1991) (triclinic P1, a = 6.542(2) $\AA$, $\mathrm{b}=6.677(<1) \AA, \mathrm{c}=10.287(2) \AA, \alpha=87.05(1)^{\circ}$, $\left.\beta=80.09(2)^{\circ}, \gamma=79.17(2)^{\circ}\right)$. Form I has two independent by symmetry molecules in the asymmetric unit. The overlay of them shows that their intramolecular geometries differ significantly considering the cyclohexanone moiety (Figure 1). This means that tibolone shows two different half-chair conformers in form I, while form II contains just one molecule and its intramolecular geometry matches well with one of the two molecules in form I (Figure 1). 


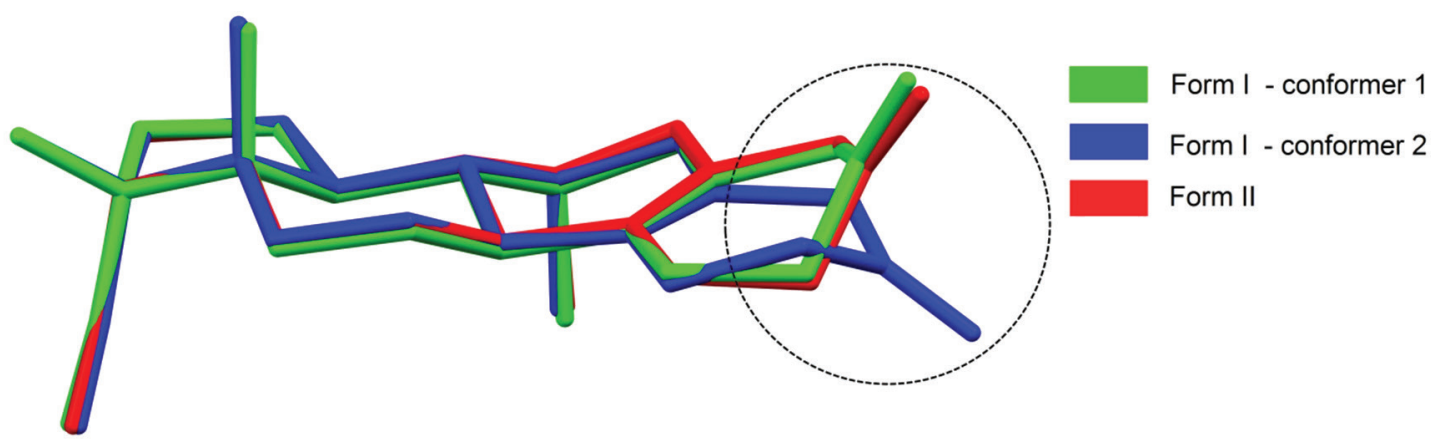

FIGURE 1 - Perspective view showing the superposition of form I (conformers 1 and 2 in green and blue, respectively) and form II (in red) of tibolone. The molecular backbones were generated from the known crystal structures (Declercq, Van Meerssche, Zeelen, 1984; Schouten, Kanters, 1991). The hydrogen atoms were hidden for clarity.

Form I is the most thermodynamically stable crystal form and preferentially used in formulations (Sas, Van Doornum, 1991). Form I is obtained by crystallizing tibolone in polar solvents such as acetonitrile or acetone. Form II can be obtained by crystallization in nonpolar solvents as hexane and toluene. However, the crystallization of both forms can occur concurrently. Therefore, as the degree of supersaturation and temperature are not easily controlled on an industrial scale, there is the possibility of a mixture of polymorphs in raw materials (Boerrigter et al., 2002).

There are descriptions of tibolone polymorphs' characterization by Powder X-ray Diffraction (PXRD), Polarized-light Optical Microscopy (POM), Scanning Electron Microscopy (SEM), Raman Spectroscopy (RS), Infrared Spectroscopy (IR), Differential Scanning Calorimetry (DSC) and Thermogravimetry (TG) (Sas, Van Doornum, 1991; Boerrigter et al., 2002; Araujo et al., 2010a, Araujo et al., 2010b). Nevertheless, to the best of our knowledge, there have been no published papers studying the influence of tibolone polymorphs on the physicochemical quality of tablets, particularly with respect to aqueous solubility and dissolution profiles. Thus, the aims of this study were to study the solubility and the dissolution properties of tibolone forms I and II.

\section{MATERIAL AND METHODS}

\section{Material}

Tibolone, British Pharmacopoeia Chemical Reference Substance (BPCRS), batch number 3053 and with a declared content of $99.2 \%$, was purchased from British Pharmacopoeia (London, United Kingdom). Tibolone raw material was acquired from Shanghai BioTech Co., Ltd. ${ }^{\mathrm{TM}}$ (Shanghai, Shanghai, China). Livial ${ }^{\mathrm{TM}}$ tablets (Shering-Plough ${ }^{\mathrm{TM}}$, São Paulo, São Paulo, Brazil) containing $2.5 \mathrm{mg}$ of tibolone were purchased from the local market. Toluene, pyridine, hydrochloric acid, sodium hydroxide and potassium dihydrogen phosphate were purchased from Vetec ${ }^{\mathrm{TM}}$ (Rio de Janeiro, Rio de Janeiro, Brazil), acetone and glacial acetic acid from Proquímios ${ }^{\mathrm{TM}}$ (Rio de Janeiro, Rio de Janeiro, Brazil), citric acid from Isofar $^{\mathrm{TM}}$ (Duque de Caxias, Rio de Janeiro, Brazil) and sodium lauryl sulfate from Dinâmica ${ }^{\mathrm{TM}}$ (Diadema, São Paulo, Brazil). These reagents were of analytical grade. Acetonitrile and methanol were of High Performance Liquid Chromatography (HPLC) grade and were obtained from Vetec ${ }^{\mathrm{TM}}$ (Rio de Janeiro, Rio de Janeiro, Brazil). Ultrapure grade water was prepared using a Direct- $\mathrm{Q}^{\mathrm{TM}}$ water system (Millipore ${ }^{\mathrm{TM}}$, Bedford, USA) and meets U.S. Pharmacopoeia requirements.

\section{Polymorphs' recrystallization}

Recrystallization of tibolone form I was performed according to the literature (Sas, Van Doornum, 1991; Araujo et al., 2010a), with slight modifications: $2.0 \mathrm{~g}$ of tibolone raw material were dissolved at $20-25{ }^{\circ} \mathrm{C}$ in $46 \mathrm{~mL}$ of acetone, to which 12 microliters of pyridine was added. The solution was then filtered, and $12 \mathrm{~mL}$ of ultrapure water was added to the filtered solution under nitrogen and agitation. We observed the formation of a suspension. The suspension was cooled in an ice bath and stirred at $150 \mathrm{rpm}$ for 1 hour. The crystals were filtered off, washed with ultrapure water and dried at $40^{\circ} \mathrm{C}$ under vacuum in a desiccator containing silica gel as a drying agent. Thereafter, the dried crystals were sieved using stainless steel mesh and the size fraction between 106 $\mu \mathrm{m}(150 \mathrm{mesh})$ and $150 \mu \mathrm{m}$ (100 mesh) was selected for further studies.

Recrystallization of tibolone form II was performed according to the literature (Sas, Van Doornum, 1991; Araujo et al., 2010a), with slight modifications: $5.0 \mathrm{~g}$ of 
tibolone raw material was dissolved at $40{ }^{\circ} \mathrm{C}$ in $215 \mathrm{~mL}$ of toluene under agitation. This solution was allowed to cool to room temperature and was kept in a refrigerator at $5-10{ }^{\circ} \mathrm{C}$ for 72 hours. The crystals were filtered off and dried at room temperature under vacuum in a desiccator containing silica gel as a drying agent. The crystals were then sieved using stainless steel mesh and the size fraction between $106 \mu \mathrm{m}(150 \mathrm{mesh})$ and $150 \mu \mathrm{m}$ (100 mesh) was selected for further studies.

\section{Polymorphs characterization}

Tibolone forms I and II were characterized by powder X-ray diffraction (PXRD) and attenuated total reflectance/Fourier transform infrared spectroscopy (ATR/ FTIR).

The PXRD patterns were recorded at room temperature on a Rigaku ${ }^{\mathrm{TM}}$ Ultima IV (type II) X-ray diffractometer (Rigaku Co., Ltd., Tokyo, Japan). The samples were individually mounted on grooved glass slides used as sample holders. Analyses were performed using $\mathrm{Cu}-\mathrm{K} \alpha$ radiation $(\lambda=1.5418 \AA)$, at a voltage of $40 \mathrm{kV}$ and current of $30 \mathrm{~mA}$. Each pattern consisted of 1251 steps, ranging from $5^{\circ}$ to $30^{\circ}$ in $2 \theta$, with a step size of $0.02^{\circ}$ and scan speed of $1^{\circ} 2 \theta$ per minute.

ATR/FTIR spectra were obtained using an Affinity-1 Fourier Transform infrared spectrophotometer (Shimadzu $^{\mathrm{TM}}$, Tokyo, Japan) coupled to a Pike Miracle ${ }^{\mathrm{TM}}$ attenuated total reflectance sampling accessory with $\mathrm{ZnSe}$ waveguides (Pike Technologies ${ }^{\mathrm{TM}}$, Madison, Wisconsin, USA). Spectra were recorded at room temperature in the $3500-500 \mathrm{~cm}^{-1}$ range. After recording a background spectrum, the samples were placed on the crystal. In each sample, 32 scans were recorded with resolution of $4 \mathrm{~cm}^{-1}$.

\section{Solubility studies of tibolone polymorphs}

To determine the solubility of tibolone polymorphs, each form was added in excess to $25 \mathrm{~mL}$ amber glass flasks containing $10 \mathrm{~mL}$ of the following solvents: ultrapure water, $0.1 \mathrm{M} \mathrm{HCl}, 0.01 \mathrm{M} \mathrm{HCl}$, pH 3.0 citrate buffer (0.18 mol.L $\left.\mathrm{L}^{-1}\right), \mathrm{pH} 4.5$ acetate buffer $\left(0.050 \mathrm{~mol}^{-\mathrm{L}^{-1}}\right)$, pH 5.8 potassium phosphate buffer $\left(0.054\right.$ mol. $\left.\mathrm{L}^{-1}\right)$, pH 6.8 potassium phosphate buffer $\left(0.072 \mathrm{~mol}^{-\mathrm{L}^{-1}}\right)$, and $\mathrm{pH} 7.2$ potassium phosphate buffer $\left(0.085 \mathrm{~mol}^{\mathrm{L}} \mathrm{L}^{-1}\right)$. The solutions were prepared in triplicate. Subsequently, the flasks were agitated at $150 \mathrm{rpm}$ at room temperature using a shaker table Solab ${ }^{\mathrm{TM}}$ model SL 180 DT (Piracicaba, São Paulo, Brasil). After 48 hour-stirring, the concentration of each polymorph in each solvent was determined using a validated stability-indicating HPLC method.
The remaining solid was dried in a desiccator containing silica and subsequently analyzed by PXRD to verify that the resulting material was the same as the starting material.

\section{Preparation of tibolone test tablets}

In order to evaluate the influence of polymorphism on tibolone tablets, two batches were prepared: test batch 1 (containing the polymorph I) and test batch 2 (containing the polymorph II). First, a placebo test mixture was prepared using the following pharmaceutical grade excipients: lactose $(8.68 \mathrm{~g})$, starch $(1.0 \mathrm{~g})$, magnesium stearate $(50 \mathrm{mg})$ and ascorbyl palmitate $(20 \mathrm{mg})$. A $125 \mathrm{mg}$ of each sieved polymorphic form was then individually added to two separate portions of $4875 \mathrm{mg}$ of the placebo test mixture. These substances were mixed in an aluminum container by vigorous shaking. Then, portions of one average weight (100 mg) were individually added to the hole punch to produce the tablets by direct compression, using a 6-mm punch diameter and a single rotary tablet compression machine Lemaq $^{\mathrm{TM}}$ model LM08B (Diadema, São Paulo, Brazil). The compression strength was adjusted to produce tablets with hardness greater than $3.0 \mathrm{kgf}$, and the same strength was used for the production of all tablets in both batches.

Subsequently, the apparent densities $\left(\mathrm{D}_{\text {app }}\right)$ of six tablets selected at random were evaluated for each batch using the Equation (1):

$$
\mathrm{D}_{\text {app }}=m / \pi \mathrm{r}^{2} t
$$

where $m$ is tablet weight in milligrams, $r$ is tablet radius in millimeters and $t$ is tablet thickness in millimeters.

\section{Dissolution profiles of tibolone polymorphs from test tablets}

The two test tablet batches, which were prepared according to the previous section, were subjected to the dissolution test conditions described for tibolone tablets in the British Pharmacopoeia 2011 with the exception of sampling time points, that were $5,10,15,20,45$ and $60 \mathrm{~min}$, instead of a single sampling point at $45 \mathrm{~min}$, as recommended. Dissolution tests were performed in an Electrolab $^{\mathrm{TM}}$ TDT-08 L multi bath $(\mathrm{n}=8)$ dissolution test system (Mumbai, Maharashtra, India). The dissolution medium was $500 \mathrm{~mL}$ of $0.25 \% \mathrm{w} / \mathrm{v}$ solution of sodium lauryl sulfate at $37^{\circ} \mathrm{C}$. A paddle was used as a stirring apparatus at 50 revolutions per minute. Five milliliters of 
the medium were sampled at the specified sampling times, followed by immediate replacement of the withdrawn volume, and the sample was analyzed by HPLC. Six tablets were assayed from each batch.

\section{Polymorphs' quantification by HPLC}

\section{Chromatographic equipment}

Samples from solubility and dissolution studies were determined using a Shimadzu ${ }^{\mathrm{TM}}$ HPLC system series LC-10A (Kyoto, Japan), consisting of an LC AVP pump, a CLASS-VP 5.02 integration system, a DGU-14 A degasser, a 7725i manual injector with a $20 \mu \mathrm{L}$ loop, an SPD-10AVP integrated UV detector, a FCV-10ALVP valve, a CTO-10AVP column oven and an SCL-10 AVP controller.

\section{Analytical conditions}

Chromatographic separations were carried out using the following chromatographic parameters: BDS Hypersil C-18 column $\left(250 \times 4.0 \mathrm{~mm}, 5.0 \mu \mathrm{m}\right.$, Thermo Scientific ${ }^{\mathrm{TM}}$, Bellefonte, Pennsylvania, USA) at $30^{\circ} \mathrm{C}$ as a stationary phase, acetonitrile and water $(60: 40 \mathrm{v} / \mathrm{v})$ at $1.0 \mathrm{~mL} \cdot \mathrm{min}^{-1}$ as the mobile phase and UV detection at $205 \mathrm{~nm}$. Before injection, samples were filtered on PTFE hydrophilic filters (13 mm diameter, $0.50 \mu \mathrm{m}$ porosity, Advantec ${ }^{\mathrm{TM}}$ MSF, Dublin, California, USA). The volume of the sample solution injected was $20 \mu \mathrm{L}$. The samples were quantified using a calibration curve of tibolone BPCRS in the concentration range $1-25 \mu \mathrm{g} \cdot \mathrm{mL}^{-1}$.

\section{Statistical analysis}

Student's t-test at a 0.05 significance level was used to compare the solubility of forms I and II in each medium and to compare the average density of tablet batch I to the average density of tablet batch II.

\section{RESULTS AND DISCUSSION}

\section{Polymorphs' characterization}

In this work, we reproduced the recrystallization processes described in the literature with slight modifications (Sas, Van Doornum, 1991; Araujo et al., 2010a), in order to obtain forms I and II of tibolone. To obtain form I, a process of recrystallization from acetonewater was used, and to obtain form II we used toluene as a solvent. Several attempts to recrystallize form II in hexane were performed; however, contamination from form I was observed by PXRD analyzes in all cases.
After recrystallization, the dried crystals were sieved and the size fraction between $106 \mu \mathrm{m}$ and $150 \mu \mathrm{m}$ was used in further studies. We used sieving to standardize the polymorphic particle size, in order to avoid influences in our experiments. Furthermore, this process does not utilize any mechanical force that could alter the crystal structure of the polymorphs.

PXRD is the traditional technique used to identify the crystalline components of APIs because every crystal form of a compound produces its own characteristic $\mathrm{X}$-ray diffraction pattern. According to the USP general chapter on X-ray diffraction, the agreement in the $2 \theta$-diffraction angles between specimen and reference is within $0.2^{\circ}$ for the same crystal form, while relative intensities between specimens and references may vary considerably due to preferred orientation effects (United, 2015).

PXRD identification of crystals after recrystallization was carried out by comparing experimental data with calculated Bragg reflections from their single-crystal XRD structure (Declercq, Van Meerssche, Zeelen, 1984; Schouten, Kanters, 1991). The results are shown in Figure 2 and Table I.

As observed in Figure 2 and Table I, the calculated Bragg peaks of form I match the experimental PXRD pattern of tibolone obtained by crystallizing in acetonewater and there was no unidentified peak, showing that form II and other crystalline phases are absent. Moreover, the experimental PXRD pattern of tibolone crystals obtained from recrystallization in toluene are in good agreement with the calculated Bragg peaks of form II; no unidentified peak was observed in this sample.

In order to confirm PXRD results, we performed FTIR-ATR analyses. ATR was used to eliminate the possibility of polymorphic transformations that can occur during the high pressure used in the preparation of $\mathrm{KBr}$ disks. The results are shown in Figure 3 and Table II.

Solid state spectroscopy (IR, Raman, and NMR) has become integral techniques for the physical characterization of pharmaceutical solids. IR and Raman spectroscopy are techniques which provide spectra based on the vibrational modes of the molecules. In many cases, IR and/or Raman spectra can identify polymorphic forms. Both techniques provide information on the structure and molecular conformation of the solid (Brittain, 2009).

As observed in Table II, recorded FTIR spectra of crystals were similar to those previously reported for polymorphs I and II using the ATR accessory (Araujo et al., 2010a). The differences in the spectra of forms I and II were attributed the conformational differences between the polymorphs: form II (triclinic) presents only 


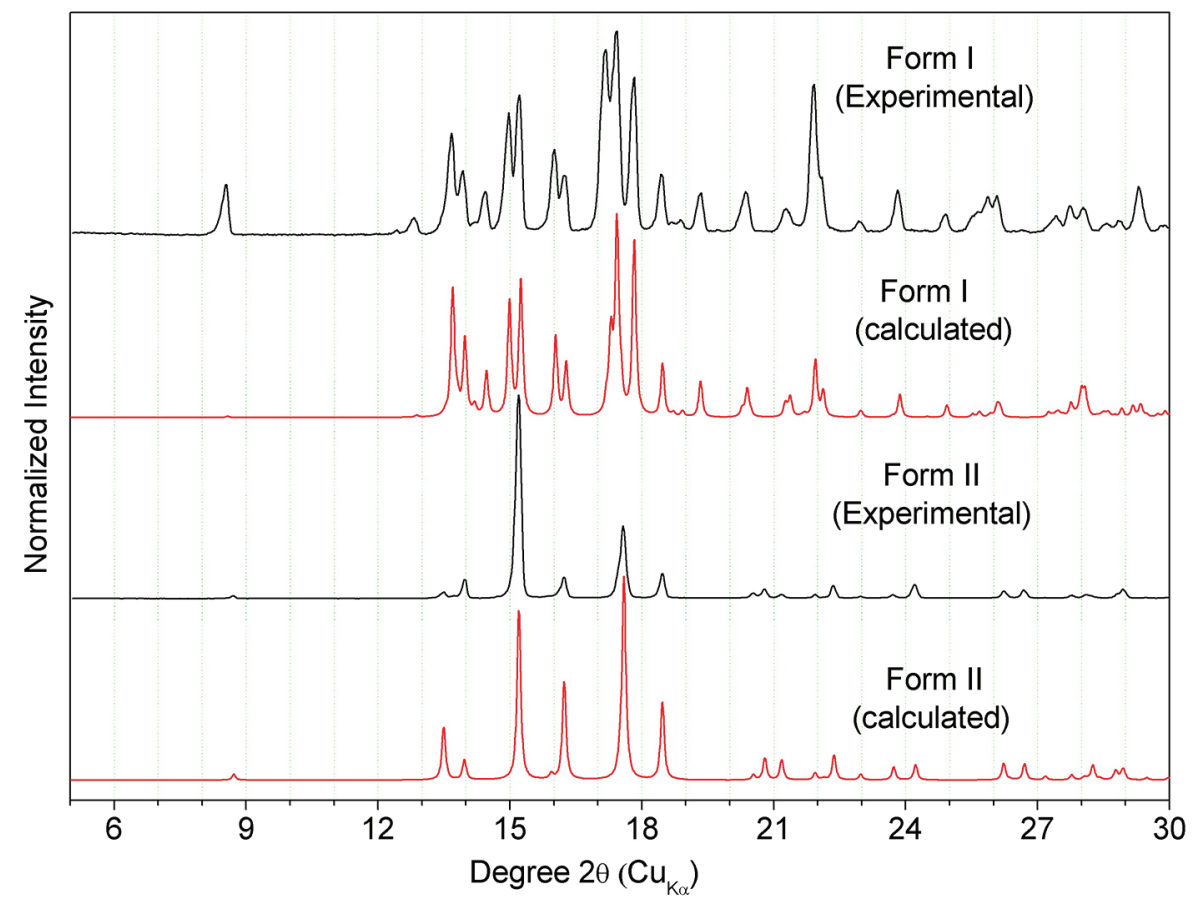

FIGURE 2 - Calculated (Declercq, Van Meerssche, Zeelen 1984; Schouten, Kanters, 1991) and experimental PXRD pattern of forms I and II of tibolone.

TABLE I - X-ray diffraction peaks (Positions in $2 \theta\left(\mathrm{Cu}_{\mathrm{K} \alpha}\right)$ ) from simulated patterns of tibolone forms I and II in comparison with the experimental PXRD diffractograms of samples obtained from the recrystallization procedures

\begin{tabular}{|c|c|c|c|}
\hline $\begin{array}{c}\text { Form I (Calculated) } \\
\text { (Declercq, Van Meerssche, } \\
\text { Zeelen, 1984) } \\
\mathbf{2 \theta}\end{array}$ & $\begin{array}{c}\text { Form I (experimental) } \\
2 \theta\end{array}$ & $\begin{array}{c}\text { Form II (Calculated) } \\
\text { (Schouten, Kanters, 1991) } \\
2 \theta\end{array}$ & $\begin{array}{c}\text { Form II (experimental) } \\
\mathbf{2 \theta}\end{array}$ \\
\hline 8.57 & 8.57 & - & - \\
\hline- & - & 8.72 & 8.71 \\
\hline 12.88 & 12.87 & - & - \\
\hline- & - & 13.49 & 13.49 \\
\hline 13.53 & - & - & - \\
\hline 13.70 & 13.72 & - & - \\
\hline 13.81 & - & - & - \\
\hline- & - & 13.96 & 13.97 \\
\hline 13.98 & 13.97 & - & - \\
\hline 14.19 & - & - & - \\
\hline 14.47 & 14.52 & - & - \\
\hline 14.99 & 15.02 & - & - \\
\hline- & - & 15.20 & 15.19 \\
\hline 15.25 & 15.27 & - & - \\
\hline- & - & - & - \\
\hline- & - & 15.94 & - \\
\hline 16.04 & 16.12 & - & - \\
\hline- & - & 16.23 & 16.23 \\
\hline 16.28 & 16.32 & - & - \\
\hline 17.20 & - & - & - \\
\hline 17.29 & - & - & - \\
\hline 17.30 & - & - & - \\
\hline
\end{tabular}


TABLE I - X-ray diffraction peaks (Positions in $2 \theta\left(\mathrm{Cu}_{\mathrm{K} \alpha}\right)$ ) from simulated patterns of tibolone forms I and II in comparison with the experimental PXRD diffractograms of samples obtained from the recrystallization procedures (cont.)

\begin{tabular}{|c|c|c|c|}
\hline $\begin{array}{c}\text { Form I (Calculated) } \\
\text { (Declercq, Van Meerssche, } \\
\text { Zeelen, 1984) } \\
2 \theta\end{array}$ & $\begin{array}{c}\text { Form I (experimental) } \\
\qquad 2 \theta\end{array}$ & $\begin{array}{c}\text { Form II (Calculated) } \\
\text { (Schouten, Kanters, 1991) } \\
2 \theta\end{array}$ & $\begin{array}{c}\text { Form II (experimental) } \\
2 \theta\end{array}$ \\
\hline 17.43 & 17.42 & - & - \\
\hline- & - & 17.49 & - \\
\hline 17.52 & - & - & - \\
\hline- & - & 17.59 & 17.57 \\
\hline- & - & 17.68 & - \\
\hline 17.83 & 17.87 & - & - \\
\hline 18.47 & 18.52 & 18.47 & 18.47 \\
\hline 18.72 & - & - & - \\
\hline 18.92 & 18.92 & - & - \\
\hline 19.33 & 19.37 & - & - \\
\hline 20.28 & - & - & - \\
\hline 20.39 & 20.37 & - & - \\
\hline 20.47 & - & - & - \\
\hline- & - & 20.54 & 20.53 \\
\hline- & - & 20.80 & 20.79 \\
\hline- & - & 21.18 & 21.17 \\
\hline 21.26 & - & - & - \\
\hline 21.37 & 21.32 & - & - \\
\hline 21.54 & - & - & - \\
\hline 21.62 & - & - & - \\
\hline 21.70 & - & - & - \\
\hline 21.94 & 21.92 & 21.94 & 21.93 \\
\hline 22.12 & - & - & - \\
\hline- & - & 22.13 & - \\
\hline 22.23 & - & - & - \\
\hline- & - & 22.37 & 22.35 \\
\hline 22.96 & - & - & - \\
\hline- & - & 22.98 & 22.97 \\
\hline 22.99 & 23.07 & - & - \\
\hline 23.70 & - & - & - \\
\hline- & - & 23.73 & 23.71 \\
\hline 23.86 & - & - & - \\
\hline 23.87 & 23.87 & - & - \\
\hline- & - & 24.22 & 24.19 \\
\hline 24.48 & - & - & - \\
\hline 24.94 & 24.97 & - & - \\
\hline 25.53 & - & - & - \\
\hline 25.68 & 25.67 & - & - \\
\hline 25.92 & - & - & - \\
\hline 26.08 & - & - & - \\
\hline 26.14 & 26.17 & - & - \\
\hline - & - & 26.23 & 26.23 \\
\hline 27.25 & - & - & - \\
\hline- & - & 26.37 & - \\
\hline- & - & 26.70 & 26.69 \\
\hline
\end{tabular}


TABLE I - X-ray diffraction peaks (Positions in $\left.2 \theta\left(\mathrm{Cu}_{\mathrm{K} \alpha}\right)\right)$ from simulated patterns of tibolone forms I and II in comparison with the experimental PXRD diffractograms of samples obtained from the recrystallization procedures (cont.)

\begin{tabular}{|c|c|c|c|}
\hline $\begin{array}{c}\text { Form I (Calculated) } \\
\text { (Declercq, Van Meerssche, } \\
\text { Zeelen, 1984) } \\
2 \theta \\
\end{array}$ & $\begin{array}{c}\text { Form I (experimental) } \\
2 \theta\end{array}$ & $\begin{array}{c}\text { Form II (Calculated) } \\
\text { (Schouten, Kanters, 1991) } \\
2 \theta\end{array}$ & $\begin{array}{c}\text { Form II (experimental) } \\
2 \theta\end{array}$ \\
\hline- & - & 27.18 & - \\
\hline 27.33 & 27.37 & - & - \\
\hline 27.41 & - & - & - \\
\hline 27.47 & - & - & - \\
\hline 27.56 & - & - & - \\
\hline 27.76 & - & - & - \\
\hline- & - & 27.78 & 27.77 \\
\hline 27.82 & 27.82 & - & - \\
\hline 27.91 & - & - & - \\
\hline 27.99 & - & - & - \\
\hline 28.02 & - & - & - \\
\hline - & - & 28.06 & - \\
\hline 28.08 & - & - & - \\
\hline- & - & 28.14 & 28.11 \\
\hline 28.16 & 28.12 & - & - \\
\hline- & - & 28.26 & - \\
\hline 28.33 & - & - & - \\
\hline 28.42 & - & 28.42 & - \\
\hline 28.50 & - & - & - \\
\hline 28.59 & - & - & - \\
\hline 28.61 & 28.67 & - & - \\
\hline 28.75 & - & - & - \\
\hline 28.91 & 28.92 & 28.91 & 28.83 \\
\hline- & - & 28.96 & 28.93 \\
\hline 29.17 & - & - & - \\
\hline 29.33 & 29.32 & - & - \\
\hline 29.35 & - & - & - \\
\hline 29.36 & - & - & - \\
\hline 29.48 & - & - & - \\
\hline- & - & 29.49 & - \\
\hline- & - & 29.58 & - \\
\hline- & - & - & - \\
\hline 29.51 & - & - & - \\
\hline 29.74 & - & - & - \\
\hline 29.90 & 29.87 & - & - \\
\hline- & - & 29.98 & - \\
\hline 30.06 & 30.02 & - & - \\
\hline
\end{tabular}

one conformation, while form I (monoclinic) can exist in two-half-chair conformations (Figure 1). For this reason, $\mathrm{C}-\mathrm{H}$ and $\mathrm{O}-\mathrm{H}$ bands are split in the IR spectrum of form I (Araujo et al., 2010a).

Therefore, the results of PXRD and FTIR-ATR showed that both forms were successfully crystallized in this work with a high degree of polymorphic purity.

\section{Solubility studies of tibolone polymorphs}

Values of solubility of sieved tibolone polymorphic forms I and II in different aqueous solvents at $25^{\circ} \mathrm{C}$ are shown in Figure 4.

As demonstrated in Figure 4, the solubility of form II is statistically higher in water, $0.01 \mathrm{~mol} . \mathrm{L}^{-1} \mathrm{HCl}$ and 

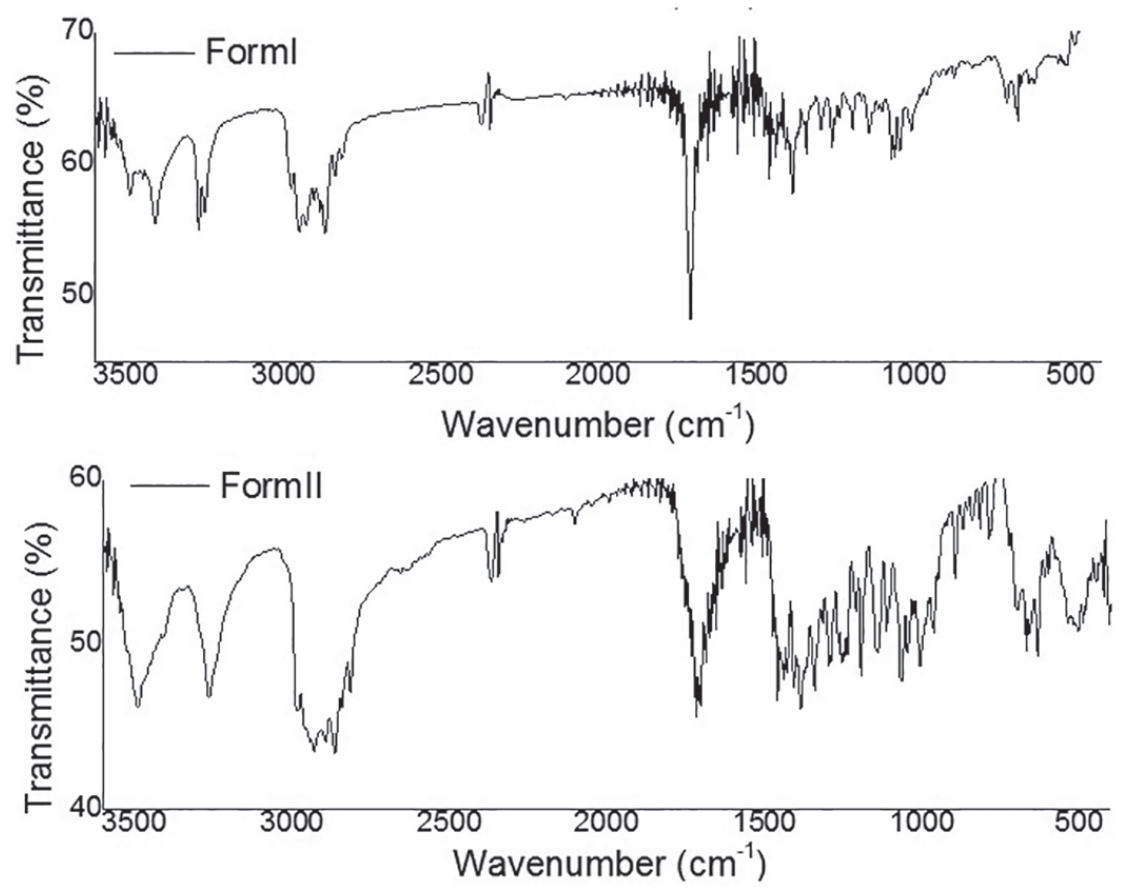

FIGURE 3 - Experimental FTIR-ATR spectra of tibolone forms I and II.

TABLE II - Major absorption bands from FTIR-ATR spectra $\left(300-3500 \mathrm{~cm}^{-1}\right)$ of tibolone forms I and II in comparison with reported values (Araujo et al., 2010a)

\begin{tabular}{cccc}
\hline $\begin{array}{c}\text { Form I (Araujo et al., 2010a) } \\
\left(\mathbf{c m}^{-1}\right)\end{array}$ & $\begin{array}{c}\text { Form I (experimental) } \\
\left(\mathbf{c m}^{-1}\right)\end{array}$ & $\begin{array}{c}\text { Form II (Araujo et al., 2010a) } \\
\left(\mathbf{c m}^{-1}\right)\end{array}$ & $\begin{array}{c}\text { Form II (experimental) } \\
\left(\mathbf{c m}^{-1}\right)\end{array}$ \\
\hline 3251 (C-H stretching) & 3252 & $3265(\mathrm{C}-\mathrm{H}$ stretching $)$ & 3265 \\
3270 (C-H stretching) & 3269 & $3489(\mathrm{OH}$ stretching $)$ & 3489 \\
3407 (OH stretching) & 3408 & & \\
3488 (OH stretching) & 3489 & & \\
\hline
\end{tabular}

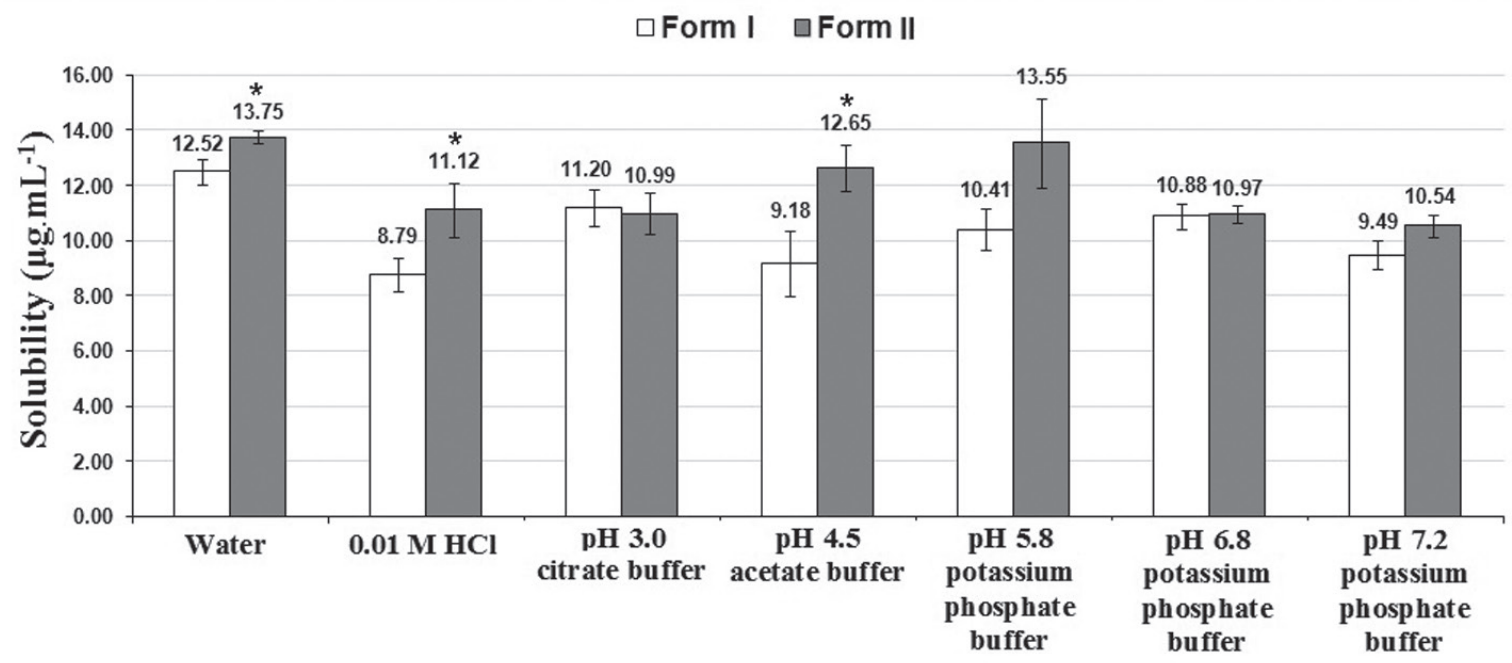

FIGURE 4 - Solubility values of tibolone forms I and II at $25^{\circ} \mathrm{C}$. Values of form II marked with asterisks differ statistically from solubility values of form I at a significance level of $5 \%$. 
pH 4.5 acetate buffer ( $\mathrm{p}$ values of $0.04,0.01$ and 0.001 respectively). Form II is about 1.10-, 1.26-, and 1.38-times more soluble in ultrapure water, $0.01 \mathrm{M} \mathrm{HCl}$ and $\mathrm{pH} 4.5$ acetate buffer, respectively, than form I. In other solvents tested, there was no statistical difference between the solubility of polymorphs. Moreover, solubility for both forms does not seem to be $\mathrm{pH}$-dependent at 48 hours. In general, when polymorphs of the same molecule (including API) are compared, the solid-state phase with a lower melt point MP and thus a higher lattice free energy is expected to have a higher equilibrium solubility and faster dissolution rate (Khankari, Grant, 1995). In the case of tibolone polymorphs, it cannot be confirmed, since Boerrigter et al. (2002) demonstrated that the melt point of form I is $170{ }^{\circ} \mathrm{C}$ and form II exhibited transition to the form I at $144{ }^{\circ} \mathrm{C}$. Nevertheless, the equilibrium solubility differences are predictable from the crystal packing in this case. Both packings present a 1D infinite network stabilized by intermolecular hydrogen bonds involving the donor/acceptor hydroxyl/carboxyl molecular extremities (Figure 5). However, in form I, the parallel 1D network is stacked in a wavy fashion, whereas parallel layers are observed in form II (Figure 5). It is reasonable to consider that the solvent-solute interaction during the dissolution process is more difficult in the wavy stacking than in the layered one, which justifies the observation that form I is less soluble than form II.
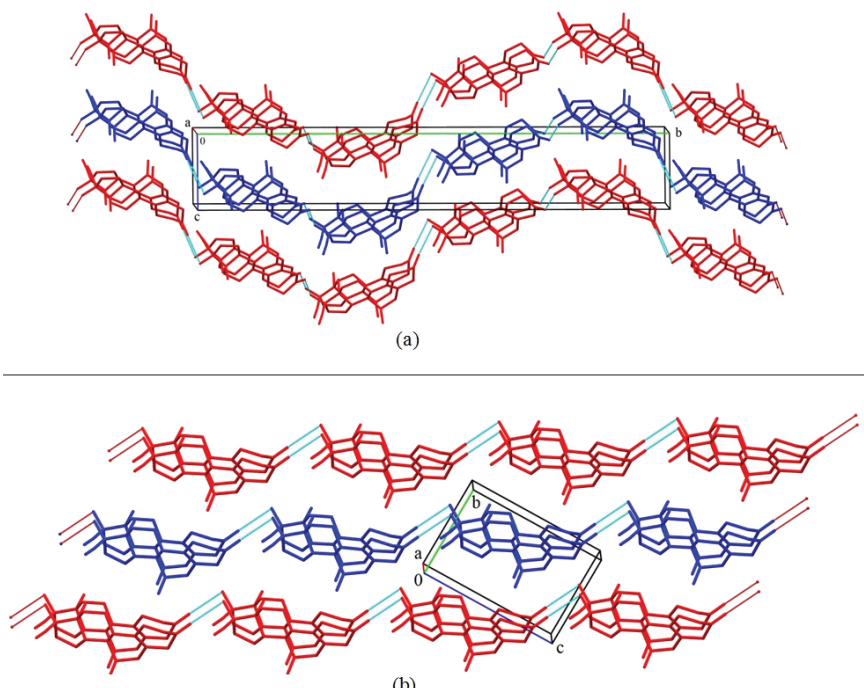

(b)

FIGURE 5 - Packing of forms I (a) and II (b) of tibolone projected onto their respective $b c$ planes (011).

The PXRD patterns (Figure 6) show that the solid material in equilibrium with the solutions used to determine solubility are constituted only by the respective crystal form used as starting material of Form I and II.
That is means, no phase transition takes place during the solubility determination experiment.

\section{Dissolution profiles of tibolone polymorphs from test tablets}

Given that the bioavailability of a drug product depends on the dissolution of the drug from the dosage form as well as solubility, we have prepared test batches of tibolone tablets containing polymorphs I and II and then perform dissolution profiles on these products. For the preparation of tablets, the excipients were selected based on the qualitative composition of Livial ${ }^{\mathrm{TM}} 2.5 \mathrm{mg}$ tablets (reference product on Brazil). As the quantitative composition is not reported by the manufacturer, we used commonly reported amounts of each excipient, based on the literature (Rowe, Sheskey, Quinn, 2009). Moreover, we used a direct compression process to avoid possible transitions in the crystal structure of tibolone polymorphs, which can occur due to the high humidity present in wet granulation. The results of dissolution profiles are shown in Figure 7.

Figure 7 clearly shows the effect of polymorphism on the dissolution of tibolone from tablets. Firstly, we calculated the density of each batch to verify whether the dissolution rate differences are not due to different compaction states of the tablets. The average tablet relative densities for batch 1 and batch 2 were $1.180 \pm$ 0.017 and $1.164 \pm 0.019 \mathrm{mg} . \mathrm{cm}^{-3}$, respectively, and were not statistically different $(\mathrm{P}=0.15)$. Diameter, thickness and average mass for batch 1 were $6.02 \pm 0.01 \mathrm{~mm}, 2.97$ $\pm 0.03 \mathrm{~mm}$ and $99.75 \pm 0.76 \mathrm{mg}$, respectively $(\mathrm{n}=6)$. Diameter, thickness and average mass for batch 2 were $6.03 \pm 0.01 \mathrm{~mm}, 3.00 \pm 0.03 \mathrm{~mm}$ and $99.73 \pm 0.61 \mathrm{mg}$, respectively $(n=6)$.

Since tibolone tablets have a small amount of active principle concerning excipients $(2.5 \%$ of active principle in samples), it was not possible to identify the polymorphic form of tablets by XRPD or FTIR-ATR. For this reason, we did not compare the dissolution of Livial ${ }^{\mathrm{TM}}$ $2.5 \mathrm{mg}$ with the Form I and Form II test batches, since any dissolution difference between these batches and Livial ${ }^{\mathrm{TM}}$ could be attributed to production process variables, and not the polymorphic composition, therefore not adding information to the objectives of this work.

Because the solubility of tibolone form II is slightly higher in some aqueous solvents, it was expected that the dissolution of form II from tablets would be slightly higher. Nevertheless, in all sampling time points, the dissolution of form II was significantly lower. To exclude the possibility of experimental errors, we repeated the 

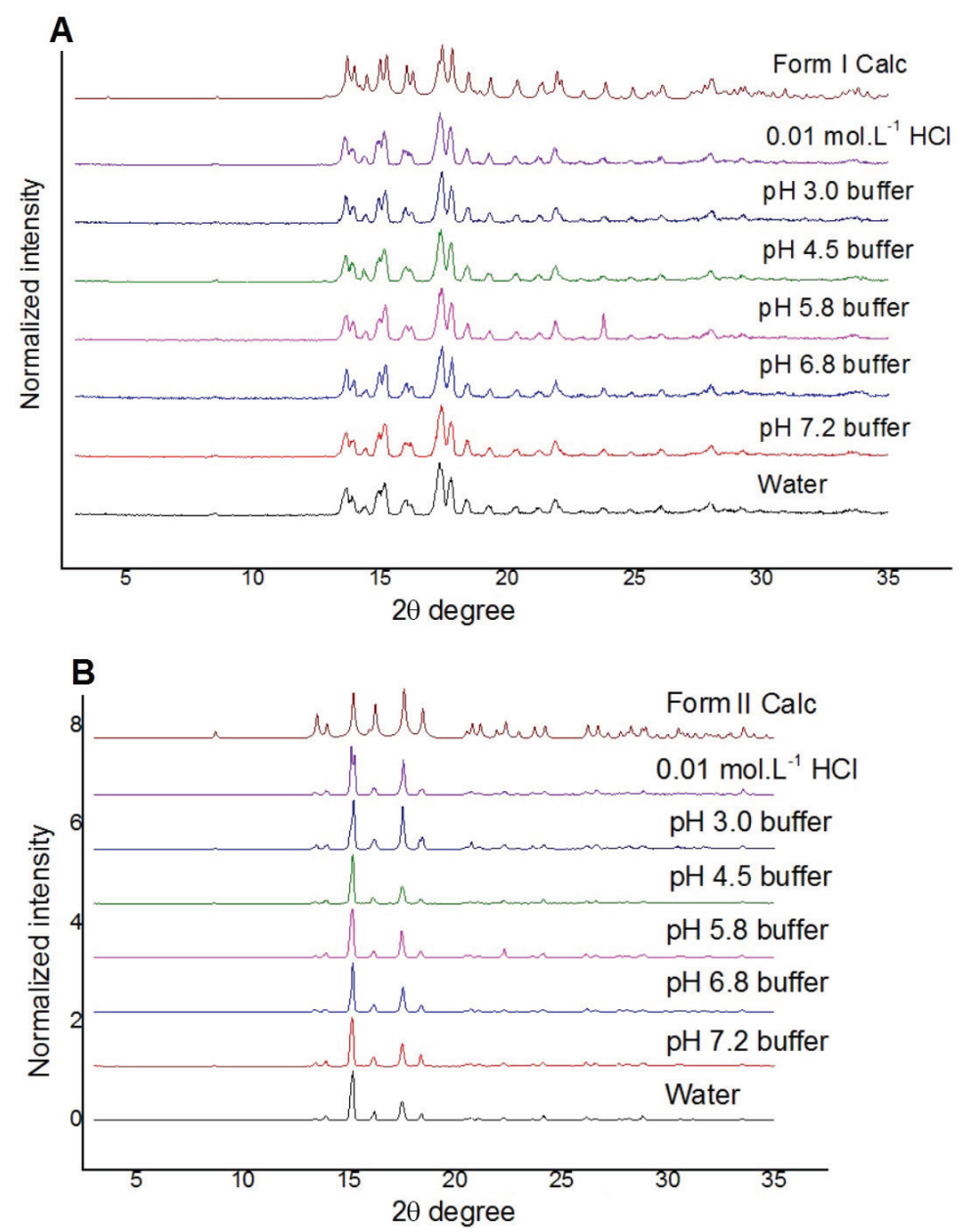

FIGURE 6 - Experimental PXRD patterns of the residual solid materials in equilibrium with the solution prepared from the tibolone forms I and II. The calculated PXRD pattern of the tibolone forms I and II are included.

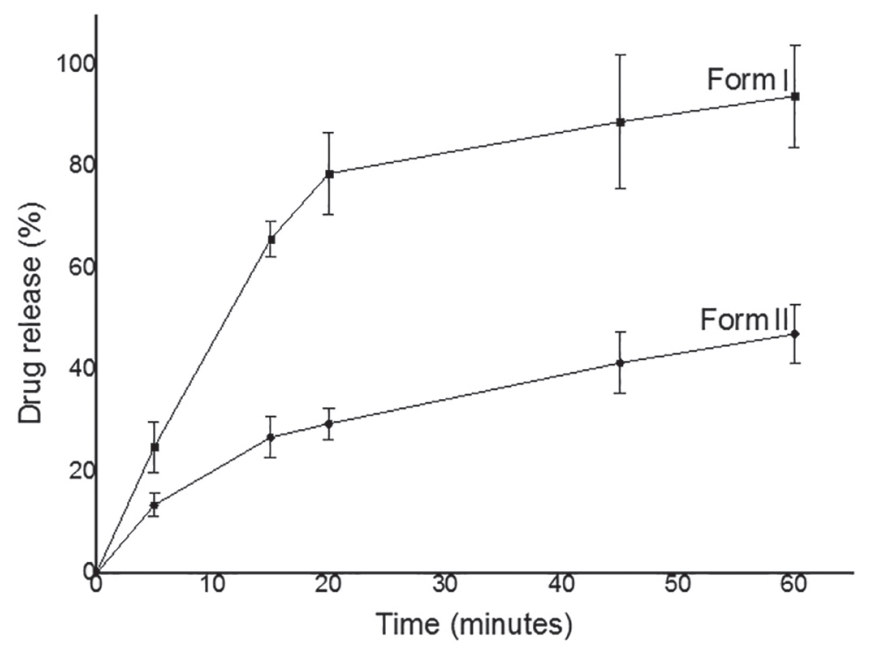

FIGURE 7 - Dissolution profiles of tablets containing tibolone forms I and II. Dissolution medium: $500 \mathrm{~mL}$ of $0.25 \% \mathrm{w} / \mathrm{v}$ solution of sodium lauryl sulfate at $37^{\circ} \mathrm{C}$; stirring apparatus: paddle at $50 \mathrm{rpm}$. Six tablets were assayed for each batch. Error bars represent standard deviations. experiments and confirmed the results. These findings can be explained by considering that several factors can affect the dissolution rate of drugs from tablets besides drugdrug intermolecular interactions, such as: particle size, dosage form, formulation technology, dissolution method, binder concentration, tablet hardness, storage conditions, excipients, drug-excipient interactions, etc.

The only above-mentioned factor that was not strictly controlled was drug-excipient interaction, since each polymorph can interact with excipients in a particular way based on its crystal packing. Thus, we suppose that this factor is responsible for the lowest dissolution of tibolone form II. This hypothesis is corroborated by the work of Araujo et al. (2010b), in which the authors evaluated compacted binary mixtures of each tibolone polymorph and excipients by differential scanning calorimetry (DSC) and HPLC. The authors demonstrated that there are distinct chemical interactions between tibolone polymorphs and some excipients used in tablets. 
Another factor that may cause a lower concentration of tibolone after performing dissolution tests on tablets containing polymorph II, could be the greater instability of tibolone form II compared to form I. However, the analysis of chromatograms obtained after 60 minutes of dissolution testing showed no higher degradation of form II compared to form I (Figure 8).

According to the FDA (2002), when differences in the aqueous solubility and dissolution rate of polymorphs of a drug substance are sufficiently large, the bioavailability is altered, and it is consequently difficult to formulate a bioequivalent drug product using a different polymorph.
Therefore, only form I is acceptable for the preparation of tablet forms, since the substitution of form I to form II can significantly harm the dissolution of tibolone from tablets and consequently alter the bioavailability of the drug product, compromising the achievement of the desired therapeutic response.

The possible impact of tibolone polymorphism on bioavailability and consequently on the clinical efficacy of marketed drug products is of great interest for public health and for academic or industrial fields. Thus, regulatory agencies should stimulate efforts for studies of properties of the different crystalline forms of drugs.
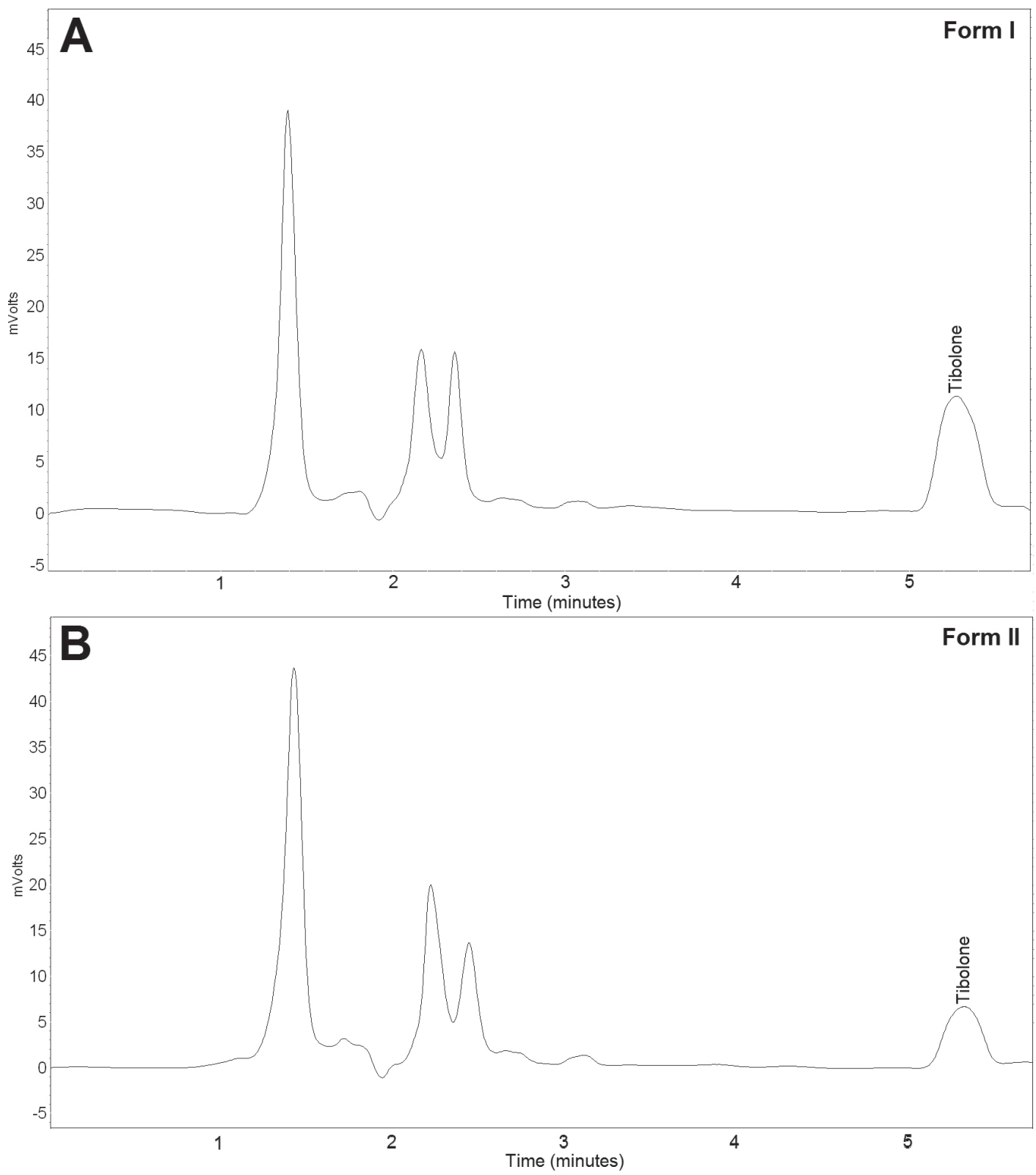

FIGURE 8 - Chromatograms of samples obtained after the 60 minute dissolution test from tablets containing form I (A) and tablets containing form II (B) of tibolone. 


\section{CONCLUSIONS}

The solubility studies demonstrated that form II is statistically more soluble in water, $0.01 \mathrm{~mol} . \mathrm{L}^{-1} \mathrm{HCl}$ and $\mathrm{pH} 4.5$ acetate buffer, with $\mathrm{p}<0.05$.

Dissolution studies of test tablets containing tibolone forms I and II showed a significant effect of the polymorphism on the dissolution of tibolone from tablets, since the release of polymorphic form II was lower than the release of form $\mathrm{I}$.

The results show the influence of tibolone polymorphs on the quality of tablets. Moreover, it is reported that form $\mathrm{I}$ is the most thermodynamically stable crystal form (Sas, Van Doornum, 1991). Therefore, only form I is acceptable for the preparation of tablets.

Based on these results, we propose that pharmaceutical industries should perform polymorphic quality control on tibolone raw materials using X-ray diffraction analysis and infrared spectroscopy in order to avoid further problems of dissolution on finished drug products.

\section{ACKNOWLEDGEMENTS}

We thank FAPEMIG (APQ-02486-14; APQ-0027314; CEX-RED-00010-14; PPM-00533-16), FINEP (Refs. 134/08 and 0336/09), CAPES (PNPD-2011) and CNPq (448723/2014-0; 308162/2015-3) for their financial support. We also thank CNPq, CAPES, and FAPEMIG for research fellowships (RB, JSL, ACD, and MBA).

\section{REFERENCES}

Boerrigter SXM, Van Den Hoogenhof CJM, Meekes H, Bennema P, Vlieg E, Van Hoof PJCM. In situ observation of epitaxial polymorphic nucleation of the model steroid methyl analogue 17 norethindrone. J Phys Chem. 2002;106(18):4725-31.

British Pharmacopoeia. London: British Pharmacopoeia Convention; 2011.

Brittain HG. Polymorphism in pharmaceutical solids. $2^{\text {nd }}$ ed. New York: Healthcare Informs; 2009.

Araujo GLB, Faria DLA, Zaim MH, Carvalho FMS, Andrade FRD, Matos JDR. Thermal studies on polymorphic structures of tibolone. J Therm Anal Calorim. 2010a;102(1):233-41.

Araujo GLB, Salvio-Neto H, Zaim MH, Matos JR. Drug excipient interaction study with polymorphic forms of Tibolone. Lat Am J Pharm. 2010b;29(3):472-6.
De Jongh HP, Van Vliet NP. 7-alpha-methyl-steroids of the oestrane series. US Patent No.3.340.279. Organon; 1967.

Declercq JP, Van Meerssche M, Zeelen FJ. Conformational analysis of 3-oxo 5(10)-unsaturated steroids. Single-crystal $\mathrm{X}$-ray structure analysis of 17 -hydroxy-7 $\alpha$-methyl-19-nor-17 $\alpha$ pregn-5(10)-en-20-yn-3-one. Neth Chem Soc. 1984;103(5):1457.

Delori A, Friščić T, Jones W. The role of mechanochemistry and supramolecular design in the development of pharmaceutical materials. CrystEngComm. 2012;14(7):2350-62.

FDA. U.S. Food and Drug Administration. Considerations of polymorphism in pharmaceutical solids: abbreviated new drug applications. 2002. [cited 2016 Dec 08]. Available from: http://www.fda.gov/ohrms/dockets/ac/02/briefing/3900B1_04 Polymorphism.htm.

Karabas I, Orkoula MG, Kontoyannis CG. Analysis and stability of polymorphs in tablets: the case of risperidone. Talanta. 2007;71(3):1382-6.

Kenemans P, Speroff L. Tibolone: clinical recommendations and practical guidelines: a report of the International Tibolone Consensus Group. Maturitas. 2005;51(1):21-8.

Khankari RK, Grant DJW. Pharmaceutical hydrates. Thermochim Acta. 1995;248(C):61-79.

Rowe RC, Sheskey PJ, Quinn ME. Handbook of pharmaceutical excipients. $6^{\text {th }}$. ed. Washington: Pharmaceutical Press; 2009.

Sas GAJMT, Van Doornum EM. Pharmaceutical composition which contains a pharmaceutically suitable carrier and the compound having the structure (7-alpha,17-alpha)-17-hydroxy7-methyl-19-nor-17-pregn-5(10)-en-20-yn-3-one. U.S. Patent 5.037.817. Akzo Nobel N.V.; 1991.

Schouten A, Kanters JA. Structure of the triclinic modification of $17 \beta$-hydroxy-19-nor-7 $\alpha$-methyl-17 $\alpha$-pregn-5(10)-en-20-yn3-one. Acta Cryst Section C. 1991;47(8):1754-6.

United States Pharmacopeia. 38 ed. NF. National Formulary 33. Rockville: United States Pharmacopeial Convention; 2015.

Received for publication on $20^{\text {th }}$ December 2016 Accepted for publication on $10^{\text {nd }}$ August 2017 